\title{
PENGARUH DARI NEPTUNE KRILL OIL PADA MANAJEMEN DISMINOREA PADA REMAJA PUTRI KELAS X DI SMA NEGERI 1 PRINGSEWU
}

\author{
Indri Retno Palupi ${ }^{1}$, Sunarsih $^{2}$ \\ ${ }^{1,2}$ Program Studi Kebidanan, Universitas Malahayati Bandar Lampung \\ Email: sunarsih.unmal@yahoo.com
}

\begin{abstract}
Neptune Krill Oil Effect on Dysmenorrhea Management of Teenage, Class X in SMA Negeri 1 Pringsewu. Results survey of Indonesian Family Planning Association (IPPA) branch of Bandar Lampung in 2014 showed that dysmenorrhea ranked number one complaint of women, as much as $65.3 \%$, in addition to irregular menstrual cycles. The prevalence of dysmenorrhea is higher in the age $10-20$ years, as much as $71.4 \%$. This study was to know the neptune krill oil effect on dysmenorrhoea management of Teenage, Class X SMAN 1 Pringsewu 2016. This study was quantitative with a quasi-experimental design. The population were all teenage girls at Class X SMAN 1 Pringsewu, total population were 193 teenages. Then, total sample were 30 teenages who experiencing dysmenorrhoea. Data analyzed by univariate and bivariate T-test. Average of dysmenorrhea pain level before being given Neptune krill oil were 8.190 (scale of 1-15), while average of dysmenorrhea pain level after being given Neptune krill oil were 4,747 (on a scale of 1-15). There was an effect of neptune Krill Oil against dysmenorrhea pain of teenages at Class X SMAN 1 Pringsewu, in 2016 ( $p$-value $=0.000)$.
\end{abstract}

Keywords: Neptune krill oil, Dysmenorrhoea management, Teenages

\begin{abstract}
Abstrak: Pengaruh Neptune Krill Oil pada Manajemen Disminorhea pada Remaja Putri Kelas X di SMA Negeri 1 Pringsewu. Hasil survei Perkumpulan Keluarga Berencana Indonesia (PKBI) cabang Bandar Lampung tahun 2014, dismenorhea menempati urutan pertama keluhan yang sering dialami wanita, sebesar $65,3 \%$ selain siklus menstruasi yang tidak teratur. Prevalensi dismenorhea lebih tinggi pada kelompok usia remaja 10-20 tahun sebesar 71,4\%. Tujuan penelitian ini diketahui pengaruh dari neptune krill oil pada manajemen disminorea pada remaja putri kelas X di SMA Negeri 1 Pringsewu tahun 2016. Jenis penelitian ini adalah kuantitatif dengan menggunakan rancangan desain eksperimen dengan menggunakan pendekatan one group pre and post test. Populasi dalam penelitian ini adalah seluruh remaja putri kelas X di SMA Negeri 1 Pringsewu yang berjumlah 193 orang, sampel dalam penelitian ini berjumlah 30 orang. Teknik sampling dalam penelitian ini menggunakan teknik accidental. Analisis data yang digunakan dalam penelitian ini univariat dan bivariat dengan uji t-test.Tingkat nyeri dismenorhea sebelum diberi Neptune krill oil pada siswi kelas X SMA Negeri 1 Pringsewu memiliki rata-rata tingkatan nyeri yaitu 8,190 (pada skala 1-15), Tingkat nyeri dismenorhea setelah diberi Neptune krill oil pada siswi kelas X SMA Negeri 1 Pringsewu memiliki Rata-rata tingkat nyeri yaitu 4,747 (pada skala 1-15). Ada pengaruh pemberian Neptune krill oil terhadap intensitas nyeri dismenorhea pada siswi kelas X SMA Negeri 1 Pringsewu Tahun 2016 ( $p$-value=0,000). Diharapkan remaja putri dapat mengetahui bahwa salah satu cara untuk mengurangi nyeri dismenorhea adalah dengan mengkonsumsi Neptune krill oil. Sehingga remaja putri dapat menerapkannya dirumah saat mengalami dismenorhea .
\end{abstract}

Kata kunci: Neptune krill oil, Manajemen disminorhea, Remaja

Masalah kesehatan reproduksi menjadi perhatian bersama, kerena bukan hanya berdampak pada individu itu sendiri, tetapi juga menyangkut berbagai aspek kehidupan. Selain itu kesehatan reproduksi merupakan salah satu parameter kemampuan negara dalam menyelenggarakan pelayanan kesehatan terhadap masyarakat (Manuaba, 2007).

Nyeri haid (dismenorhea) adalah karakteristik nyeri yang terjadi sebelum atau selama menstruasi, terjadi pada hari pertama sampai beberapa hari selama menstruasi. Hal ini adalah satu dari sekian banyak masalah ginekologi, mempengaruhi lebih dari 50\% wanita dan menyebabkan ketidak mampuan beraktifitas selama 1-3 hari tiap bulan pada wanita tersebut. Absensi pada wanita dewasa saat sekolah akibat dismenorhea mencapai 25\% (Suhartatik, 2003). Nyeri haid (dismenorhea) yang dialami saat terjadi menstruasi bisa sangat menyiksa. Kadang- 
kadang perempuan membungkukkan tubuh atau merangkak lantaran tidak mampu menahan rasa nyeri bahkan ada yang sampai berguling-guling di tempat tidur. Hal ini sangat mengganggu aktifitas perempuan sehari-hari dan dapat berdampak pada turunnya produktivitas kerja.

Neptune krill oil adalah udang kecil dilaut seperti crustacea berasal dari genus euphasia yang memiliki ukuran tubuh $1-6 \mathrm{~cm}$. sebuah spesies tertentu dari antartika (euphasia Superba) yang digunakan untuk membuat minyak krill, yang baru-baru ini terbukti unggul dalam kandungan gizi dibandingkan dengan minyak ikan lainnya. Sebuah penelitian bahwa krill oil sangat efektif dalam pengurangan nyeri dismenorhea, termasuk rasa nyeri dan gangguan emosianal, dan efeknya lebih tinggi dari dosis setara minyak ikan (Sampalis, et all, 2003).

American college of obstetricians di dapatkan dari 78 pasien yang mengkonsumsi krill oil saat menstruasi mengurangi nyeri dismenorhea dibandingkan yang tidak mengkonsumsi krill oil di dapatkan $(p<0.03)$ dapat di simpulkan bahwa neptine krill oil terbukti efektif untuk mengurangi nyeri dismenorhea pada wanita.

Berdasarkan data BKKBN tahun 2014 dalam Jurnal Kesehatan Reproduksi Remaja angka kejadian dismenore di Indonesia terdiri dari dismenorhea primer sebesar $64,8 \%$ dan sebesar 19,36\% dismenorhea sekunder. Gejala dismenorhea primer terjadi pada remaja putri 1 sampai 2 tahun setelah mengalami haid pertama yang menyebabkan remaja tersebut tidak bisa melakukan aktivitas seperti biasanya (BKKBN, 2014).

Hasil penelitian Sentra Kawula Muda Lampung (SKALA) bekerja sama dengan Crisis Children Center (CCC) tahun 2014 terhadap 300 remaja putri didapat 224 orang $(74,6 \%)$ remaja mengatakan sering mengalami gejala nyeri perut pada saat menjelang dan saat menstruasi berlangsung. Dari 224 remaja tersebut 127 orang $(56,7 \%)$ mengalami nyeri disminorhea dan 97 orang $(43,3 \%)$ mengalami nyeri premenstruasi sindrom (SKALA \& CCC, 2014).
Hasil survei Perkumpulan Keluarga Berencana Indonesia (PKBI) cabang Bandar Lampung tahun 2014, dismenorhea menempati urutan pertama keluhan yang sering dialami wanita, sebesar $65,3 \%$ selain siklus menstruasi yang tidak teratur. Prevalensi dismenorhea, dismenorhea lebih tinggi pada kelompok usia remaja 10-20 tahun sebesar 71,4\% (PKBI Bandar Lampung, 2014).

Menurut pre survei yang dilakukan di SMA Negeri 1 Pringsewu hasil dari data registrasi UKS di dapatkan kejadian disminore pada bulan januari di alami oleh $18(42,8 \%)$ orang yang mengalami disminorhea dan meningkat pada bulan Februari menjadi sebesar $24(57,2 \%)$ orang yang mengalami disminorhea (Data register UKS SMA Negeri 1, 2015).

\section{METODE PENELITIAN}

Jenis penelitian yang digunakan dalam penelitian ini adalah kuantitatif yaitu jenis penelitian yang bersifat induktif, objektif dan ilmiah dimana data yang di peroleh berupa angka-angka (score, nilai) untuk pernyataanpernyataan yang di nilai, dan dianalisis dengan analisis statistik (Notoatmodjo, 2010). Rancangan yang digunakan dalam penelitian ini adalah analitik eksperimental dengan pendekatan one group pre and post test. Lokasi penelitian akan dilakukan di SMA Negeri 1 Pringsewu. Pengambilan data dilakukan pada tanggal 01 Agustus 2016 sampai dengan 11 Agustus 2016.

Populasi dalam penelitian ini adalah seluruh remaja putri kelas $X$ di SMA Negeri 1 Pringsewu sebanyak 193 orang. Sampel dalam penelitian adalah seluruh remaja putri kelas $X$ di SMA Negeri 1 Pringsewu yang jumlah 30 orang yang didapat dengan teknik accidental sampling. Variabel independen adalah neptune krill oil dan Variabel dependen adalah dismenorhea. Analisis univariat menggunakan bantuan program komputer dan analisa bivariat menggunakan uji statistik $t$-dependen.

\section{HASIL}

\section{A. ANALISIS UNIVARIAT}

Tabel 1. Intensitas Nyeri Dismenorhea Sebelum dan Sesudah Konsumsi Neptune krill oil

\begin{tabular}{ccccccc}
\hline $\begin{array}{c}\text { Intensitas } \\
\text { Nyeri }\end{array}$ & $\mathrm{n}$ & Minimum & Maximum & Mean & Median & $\begin{array}{c}\text { Std. } \\
\text { Deviation }\end{array}$ \\
\hline Sebelum & 30 & 4,6 & 11,6 & 8,190 & 8,000 & 1,8596 \\
\hline Sesudah & 30 & 1,9 & 6,8 & 4,747 & 4,550 & 1,3918 \\
\hline
\end{tabular}


Berdasarkan tabel 1 diketahui bahwa ratarata (mean) intensitas nyeri dismenorhea sebelum konsumsi neptune krill oil pada siswi kelas X di SMA Negeri 1 Pringsewu Tahun 2016 sebanyak 8,190 dengan standar deviasi sebesar 1,8596 dan nilai tengah (median) didapatkan 8,000 serta diketahui rentang skala nyeri minimum sebelum mengkonsumsi neptune krill oil didapatkan 4,6 yang berarti seluruh responden mengalami nyeri dismenorhea. Sedangkan rata-rata (mean) intensitas nyeri dismenorhea sesudah konsumsi Neptune krill oil sebanyak 4,747 dengan standar deviasi sebesar 1,3918 dan nilai tengah (median) didapatkan 4,550 serta diketahui rentang skala nyeri minimum dan maximum didapatkan 1,9 sampai dengan 6,8 , dari data tersebut ada pengaruh yang signifikan yaitu mean sebelum 8,190 dan mean sesudah 4,747 yang berarti ada penurunan intensitas nyeri sesudah mengkonsumsi neptune krill oil .

\section{B. ANALISIS BIVARIAT}

Tabel 2. Pengaruh dari Neptune krill oil pada Manejemen Dismenorhea

\begin{tabular}{lllllll}
\hline \multicolumn{1}{c}{ Kelompok } & \multicolumn{1}{c}{ Variabel } & $\mathrm{n}$ & Mean & SD & SE & $\begin{array}{c}p- \\
\text { value }\end{array}$ \\
\hline $\begin{array}{l}\text { Nyeri } \\
\text { dismenorhea }\end{array}$ & $\begin{array}{l}\text { Nyeri dismenorhea sebelum } \\
\text { pemberian neptune krill oil } \\
\text { Nyeri dismenorhea sesudah } \\
\text { pemberian neptune krill oil }\end{array}$ & 30 & 8,190 & 1,8596 & 0,3396 & 0,000 \\
& 4,747 & 1,3918 & 0,2541 & \\
\hline
\end{tabular}

Uji statistik menunjukan bahwa nilai ratarata nyeri dismenorhea sebelum diberikan neptune krill oil sebesar 8,190 dengan standar deviasi 1,8596 dan SE 0,3396 setelah diberikan neptune krill oil didapat rata-rata nyeri 4,747 dengan standar deviasi 1,3918 dan SE 0,254, Terdapat perbedaan nilai rata-rata sebelum dan setelah diberikan neptune krill oil adalah 3,443. Hasil uji statistik didapatkan nilai $p$-value $=0,000$ yang berarti ( $p$-value $<\alpha=0,05)$. Berdasarkan data tersebut maka dapat diartikan bahwa ada pengaruh pemberian pemberian neptune krill oil pada remaja putri yang mengalami dismenorhea di SMA Negeri 1 Pringsewu tahun 2016.

\section{PEMBAHASAN}

Rata-rata nyeri dismenorhea sebelum diberikan neptune krill oil sebesar 8,190 dengan standar deviasi 1,8596 dan SE 0,3396 setelah diberikan neptune krill oil didapat rata-rata nyeri 4,747 dengan standar deviasi 1,3918 dan SE 0,254 . Terdapat perbedaan nilai rata-rata sebelum dan setelah diberikan neptune krill oil adalah 3,443 . Hasil uji statistik didapatkan nilai $p$-value $=0,000$ yang berarti ( $p$-value $<\alpha=0,05)$. Berdasarkan data tersebut maka dapat diartikan bahwa ada pengaruh pemberian pemberian neptune krill oil pada remaja putri yang mengalami dismenorhea di SMA Negeri 1 Pringsewu tahun 2016.

Menurut Potter \& Perry (2005). Nyeri menyangkut dua aspek yaitu psikologis dan fisiologis. Anurogo \& Wulandari (2011) dalam terorinya menyebutkan bahwa nyeri dismenorhea memiliki gejala yang sangat kompleks. Rendahnya kadar progesteron pada akhir fase corpus luteum. Hormon progesteron menghambat atau mencegah kontraktilitas uterus, sedangkan hormon estrogen merangsang kontraktilitas uterus. Di sisi lain, endometrium dalam fase sekresi memproduksi prostaglandin F2 sehingga menyebabkan kontraksi otot-otot polos. Jika kadar prostaglandin yang berlebihan memasuki peredaran darah, maka selain dismenorrhea dapat juga dijumpai efek lainnya seperti nausea (mual), muntah, diare, flushing (respons involunter / tak terkontrol) dari sistem syaraf.

Menurut Kumalasari, dkk (2012) penatalaksanaan dismenorrhea dapat dilakukan dengan pemberian kompres panas, istirahat dan relaksasi, pemberian analgesik, antipasmodik, estrogen dan progesteron dan pemberian sumplemen.

Krill Oil ditemukan sebagai suplemen yang berbentuk kapsul dan memiliki efek antiinflamasi. Neptune krill oil (NKO) adalah bentuk paten minyak krill oil yang umum ditemukan dalam suplemen minyak krill.

Didalam krill oil terdapat kandungankandungan yang dapat meringankan respon seseorang terhadap nyeri antara lain adalah lemak tak jenuh ganda, asam lemak omega 3, terutama asam eicosapentanoic (EPA) dan docosahexanoic acid (DHA) (Lestari,2013). Beberapa penelitian mendukung bahwa rantai asam lemak berfungsi dalam pengelolaan PMS. Asam lemak omega 3 terutama eicosapentanoic (EPA) dan docosahexanoic acid (DHA) bersama 
dengan omega 6 mensintetase enzim prostaglandin. Asam lemak omega 3 menyebabkan kurang kuatnya sekresi leukotrien dan 3 jenis prostaglandin anti impalasi yaitu PI, PE dan tromboksan. Hasilnya kontraksi miometrium dan vasokrontriksi uterus berkurang, iskemia berkurang dan rasa sakit mengilang (Cameron et all,1998 dalam Sampalis, 2003).

Asam lemak omega 3 Dosis yang dianjurkan dari krill oil adalah antara 1,000 dan 2,000 mg per hari, satu dosis gram minyak krill telah ditemukan efektif untuk menurunkan kolesterol dan gejala dismenorhea (Lestari, 2013)

Hasil penelitian ini sejalan dengan hasil penelitian yang dilakukan oleh Sampalis et all (2003), dalam penelitian itu disebutkan bahwa dalam mengatasi nyeri dismenorhea pada remaja dapat dilakukan dengan obat-obat herbal seperti omega-3 minyak ikan atau NKO Krill Oil yang cukup efektif dalam menurunkan nyeri dismenorhea.

Menurut peneliti dari pengolahan data didapatkan perbedaan rata-rata skala nyeri pada responden sebelum dan sesudah diberikan suplemen neptune krill oil. Sebelum diberikan neptune krill oil skala nyeri lebih tinggi dibandingkan setelah responden mengkonsumsi suplemen tersebut dikarenakan kandungan asam lemak omega 3 yang terdapat di dalam neptune krill oil menyebabkan penurunan kontraksi pada uterus sehingga nyeri dismenorrhea berkurang.

Ambang nyeri setiap responden berbeda. Selain itu terdapat beberapa faktor yang mempengaruhi dismenorrhea, sebelum diberikan neptune krill oil terdapat responden dengan tingkat nyeri yang rendah dikarenakan persepsi yang baik terhadap dismenorrhea, dismenorrhea merupakan rasa nyeri yang selalu menyertai menstruasi dan menganggap hal tersebut adalah hal yang biasa dirasakan.

Setelah diberikan neptune krill oil terdapat tersponden yang skala nyeri yang tinggi, hal tersebut dapat dipengaruhi oleh beberapa faktor lain seperti kelainan orgaik (kelainan pada organ reproduksi), penyakit menahun seperti anemia, serta psikologi seseorang.

Diharapkan remaja putri dapat melibatkan tenaga kesehatan dalam menangani dismenorhea terutama jika nyeri yang dirasakan dapat menyebabkan ketidakmampuan dalam beraktivitas, agar dilakukan pemeriksaan dan penanganan secara tepat.

\section{SIMPULAN}

Berdasarkan hasil analisa data dan pembahasan sebelumnya dapat disimpulkan bahwa:

1. Tingkat nyeri dismenorhea sebelum diberi Neptune krill oil pada siswi kelas X SMA Negeri 1 Pringsewu memiliki rata-rata tingkatan nyeri yaitu 8,190 (pada skala 1-15)

2. Tingkat nyeri dismenorhea setelah diberi Neptune krill oil pada siswi kelas X SMA Negeri 1 Pringsewu memiliki Rata-rata tingkat nyeri yaitu 4,747 (pada skala 1-15).

3. Ada pengaruh pemberian neptune krill oil terhadap intensitas nyeri dismenorhea pada siswi kelas X SMA Negeri 1 Pringsewu Tahun $2016(p$-value $=0,000)$

\section{SARAN}

1. UKS di SMA Negeri 1 Pringsewu diharapkan dapat memberikan Penyuluhan terhadap remaja putri tentang nyeri dismenorhea. Diharapkan remaja putri dapat mengetahui bahwa salah satu cara untuk mengurangi nyeri dismenorhea adalah dengan mengkonsumsi Neptune krill oil. Sehingga remaja putri dapat menerapkannya dirumah saat mengalami dismenorhea.

2. Dengan adanya penelitian ini menjadi inspirasi bagi peneliti untuk melakukan penelitian yang sifatnya melanjutkan atau dengan konteks yang berbeda tentang pengaruh Neptune krill oil terhadap dismenorhea pada remaja putri.

\section{DAFTAR PUSTAKA}

Anurogo. Dito \& Wulandari, Ari. 2011. Cara Jitu Mengatasi Nyeri Haid. Yogyakarta: Andi Yogyakarta.

BKKBN. 2014. Prevalensi Penderita Dismenore di Indonesia. Dalam www.jurnalkesehatanreproduksi.com (Diakses tanggal 21 Juli 2016).
Kumalasari, dkk. 2012. Kesehatan Reproduksi Untuk Mahasiswa Kebidanan dan Keperawatan. Jakarta: Salemba Medika

Lestari, Indah. 2013. Apa Itu Krill Oil?. https://www.merdeka.com/ireporters/sehat/ apa-itu-krill-oil-.html. Diakses pada Agustus 2016. 
Manuaba, Ida Bagus Gde. 2007. Memahami Kesehatan Reproduksi Wanita. Jakarta: EGC

Notoatmodjo, Soekidjo. 2010. Metodologi Penelitian Kesehatan. Jakarta: Rineka Cipta.

PKBI Bandar Lampung. 2014. Survei Kesehatan Remaja. Bandar Lampung.

Potter \& Perry. 2005. Buku Ajar Fundamental Keperawatan: Konsep, Proses \&. Praktek. Jakarta: EGC.

Sampalis, et al. 2003. Evaluation of the Effects of Neptune krill oil ${ }^{\mathrm{TM}}$ on the Management of Premenstrual
Dysmenorrhea. Altern Med Rev, 8: 171179.

Sentra Kawula Muda Lampung (SKALA). 2014. Perilaku pada Remaja Terhadap Dalam Menangani Dismenore. www.radaronline.com (Diakses pada taggal 11 Januari 2016).

SMA Negeri I. 2016. Laporan UKS. Pringsewu. Lampung.

Suhartatik. 2003. Hubungan Gejala Saat Menstruasi dengan Produktivitas Kerja Perawat di Ruang Rawat Inap Rumah Sakit Panti Rapih Yogyakarta. Yogyakarta: UGM. 